\title{
The Integration of Climate Change Issues on Local Government Planning Processes of South Africa
}

\author{
Thanyani S Madzivhandila \\ Department of Development Planning \& Management, University of Limpopo, \\ South Africa, Private Bag X1106, Sovenga, 0727 \\ thanyani.madzivhandila@ul.ac.za
}

\section{Doi:10.5901/mjss.2014.v5n20p941}

\begin{abstract}
The establishment of Local Sphere of Government in South Africa was seen as a paramount step towards ensuring successful service delivery to the poor communities in the rural areas. Planning for service delivery at a local sphere is important to integrate and include the communities through participation. In recent years, climate change emerged as one of the greatest challenge to deal with in the entire universe. Its short and long term impacts are viewed as devastating particularly to the poor communities in developing countries. Issues such as floods, drought and unprecedented weather conditions which are sometimes disastrous and associated with climate change are seen to have a huge impact to the processes of delivering services such as water and electricity. Concurrently, economic activities and livelihoods which forms financial base for local economic development of a specific local areas are also affected. This article argues that, poor communities will continue to be vulnerable victims of climate change if measures to address its effect are not strategically placed in the Integrated Development Planning (IDP) processes of local government. The purpose of this article is to provide a critical discussion on the impact of climate change on service delivery; environmental risks, hazards and service delivery; challenges faced in planning for service delivery in local government and the importance of integrating climate change issues in the IDP processes. The article concludes that in order to strategically deal with the effects of climate change on service delivery, the former should be integrated in all aspects of IDP in order to establish measure to eliminate its devastating impacts.
\end{abstract}

\section{Introduction}

Achieving developmental local government is a major challenge facing municipalities across the globe. The ability of municipalities to render services such as water, electricity, transport infrastructures and creation of employment opportunities has remained a pipe-dream particularly in rural areas because of diverse challenges that are faced (Gordon, 2005). Lack of skills and financial resources has underlined a weak facilitation of key dimensions of economic, social, institutional and environmental development in these areas. With all these challenges, climate change has emerged in recent years as one of the environmental problems that are most serious and difficult to manage (Mukheibir \& Ziervogel, 2007; Revi, 2008; Totty, 2009; Ayinde, Ajewole, Ogunlade \& Adewumi, 2010). Evidence of high temperatures, rising sea levels, low rainfall, drought, floods and acid rain which are linked to climate change, has disrupted the provision of water, electricity and destroyed houses, livelihoods and agricultural practices of the poor in rural areas (Totty, 2009).

To meet its responsibility to the people, to respond to the impacts of climate change, and to contribute to the international effort to mitigate climate change, the government of South Africa in consultation with business, labour and civil society, has drafted the National Climate Change Response White Paper of 2011. The White Paper outlines the policies, principles and strategies the country will use to respond to climate change (Department of Environmental Affairs, 2011). As a responsible global citizen with moral as well as legal obligations under the United Nations Framework Convention on Climate Change (UNFCCC) and its Kyoto Protocol, South Africa is committed to contribute a fair share to the global greenhouse gas mitigation efforts. The efforts of South African government are in line with the objectives of the Kyoto Protocol which was adopted at a meeting of the UNFCCC in Kyoto, Japan in December 1997. The Kyoto Protocol sets binding targets for industrialized countries to reduce their combined greenhouses gas emissions by at least $5 \%$ compared to 1990 levels in the period 2008 to 2012. This legally binding commitment promised to produce a historical reversal of the upward trend in emissions that started in these countries some 150 years ago (Department of Environmental Affairs, 2011).

South Africa is classified as a developing country in terms of the convention and was not obliged to adhere to the more demanding commitments placed on developed countries to the convention. However, South Africa's efforts to curb 
the effects of climate change are driven from the notion that, the government believe that global greenhouse gas reduction efforts must work in cycle with a pro-poor adaptation agenda. Such an approach will empower the poor and vulnerable and ensure human dignity, whilst endeavouring to attain environmental, social and economic sustainability. Currently, South Africa is still a signatory to the UNFCCC and had hosted its 17th Conference of the Parties (COP17) from 28 November - 9 December 2011 in Durban. The outcomes of the conference included among others the commitment by both developed and developing countries to compiling a new international agreement to reduce greenhouse gas emissions which will come into effect in 2020 and the endorsement of the Green Climate Fund to assist developing countries transition to a low carbon economy. Ironically, in South Africa, climate change issues are still only facilitated well at the national sphere of government but remain major challenge at the municipal level. According to Mukheibir \& Ziervogel (2007), local government institutions have limited financial resources and human capacity and they lack expert skills to deal with environmental problems; hence, current trend and impact of climate change problems had left majority of people devastated. There is a need for the incorporation of climate change and its potential effects into policy making and planning on range of scales including national, provincial and local spheres of government (Revi, 2008).

This article provides an argument that, in order to address challenges and problems associated with climate change; measures to address its effect should be strategically integrated in the planning processes of municipalities. The article begins with the presentation of the concept of climate change and it impacts to services delivery, the discussion focuses on the impact of climate change on the provision of services such as water and electricity. A discussion of environmental risks, hazards and service delivery follows. The article then, discusses some of the significant challenges associated with planning for service delivery. Lastly, the article presents a discussion on the importance of integrating climate change issues in municipal IDP processes with specific reference to Polokwane, Molemole and Lepelle-Nkumpi Local Municipalities.

\section{Climate Change Impacts on Service Delivery}

In recent years, reducing vulnerability to climate change has been an urgent issue in low and middle-income countries which has become a major part of any sustainable development agenda (Gordon, 2005; Mukheibir \& Ziervogel, 2007; Revi, 2008). Climate change is increasingly pointed as an important strategic economic and political concern. This is because of its impacts on economic growth rates, the lives and livelihoods of millions of people. It is difficult for municipalities that are at risk from projected climate change effects to make resources and infrastructure planning and management and increase the urgency of the need to adapt to municipal-level operation to the future effects of climate change (Revi, 2008). For example, in Capricorn District Municipality, IDP's and review reports from Lepelle-Nkumpi (2006-2011), Molemole (2008/2009) and Polokwane (2010/2011) Local Municipalities have not specifically identified climate change as a challenge to the provision of service delivery, nor do the municipalities formulated strategies to tackle its impacts. Furthermore Revi (2008) argued that, addressing complex major risks such as drought and floods is a serious public policy and adaptation management challenge for many countries. For example, in South Africa a significant number of recent disastrous events have been associated with weather conditions (for instance, year 2012 Floods in Mpumalanga and Kwazulu Natal).

Given the depth and severity of rural poverty in South Africa, climate change is proving to have borne adversarial effects on poor households in rural areas. That is, climate change is undermining South Africa's efforts to alleviate poverty and to provide for food security, environmental health and human settlement (Department of Environmental Affairs, 2004). Most of municipalities in South Africa are failing to provide for sustainable services such as clean water, energy supply and road infrastructure because of the effects of climate induced variable such as drought and floods. Drought has been associated with its impact on drinking water shortage, land use, cropping patterns and poor water resources management. In rural areas failure of municipalities to provide clean water had resulted to people being exposed to environment related health risks including those from water-washed diseases such as diarrhoea, cholera and typhoid (Revi, 2008). The next most important climate change risk is increased river line and inland flooding. For example, in countries such as India, large numbers of people are currently affected by floods for three to six month of the year and that has interrupted planning and implementation of government services particularly for the poor in rural areas (Revi, 2008). Floods are perceived to be the most dangerous event signalling the existence of climate change (Khandlhela \& May, 2006). That is, they constitute heavy rains which do not only frustrate household municipal service delivery but also impact on food production infrastructure, closure of schools, damage to traditional dwellings and sometimes loss of lives (Khandlhela \& May, 2006; Hahn, Riederer \& Foster, 2009). Climate change impacts increase the vulnerability of municipalities in dealing with environmental risk and hazard which affects facilitation of service delivery. 


\section{Environmental Risk, Hazards and Service Delivery}

Environmental management at the municipal level is still receiving a limited attention and that has led majority of people particularly in rural areas to be vulnerable to various environmental risks, hazards and disastrous events (Gordon, 2005; Revi, 2008; Roberts, 2008; Tomlinson, 2011). Poor people residing at these municipalities have continued to experience disaster associated with drought, failure of crops and lack of access to appropriate social structures (Roberts, 2008). For instance, in Molemole Municipality's IDP review report (2008/2009) water scarcity associated with drought is identifies as a major challenge facing the municipality. Municipalities are continuing to struggle with facilitating communication of adequate warning, protection, knowledge, skills and access to both material resources and to knowledge, networks and sources of support which can greatly mitigate the impacts of natural events and increase the ability of people to recover from climate induced effects (Revi, 2008; Roberts, 2008). Furthermore, Gordon (2005) argues that, these challenges are manifesting themselves in a growing tension between the need to introduce environmental issues and concerns into planning and decision-making process and the need to expedite development to address significant socio-economic needs. The fact that some of municipal officials are unaware of the link between environmental challenges and the slow pace of service delivery is continuing to cost government a lot of resources. Clear strategies to tackle environmental problems are still not well integrated to IDP's of municipalities; hence, communities are exposed to disastrous events that could have been avoided (Gordon, 2005). For example, Lepelle-Nkumpi IDP (2006-2011) identifies deforestation, overgrazing, erosion and poaching as major environmental related challenges that are being faced at the municipality; however, strategies to address such challenges are not formulated and reflected in the IDP strategic and projects phase. The need for simultaneous elevation and revision of both the environmental and development agendas to cater for an integrated planning has created a significant dilemma for local government in South Africa. Catering for private institution to participate in the integration of these issues has remained a major challenge.

The primarily responsibility for creating the right conditions and incentives for private institution to get involved and manage environmental risks and hazards impact and to make efficient investment decisions to public assets and service delivery is also a major challenge among municipalities (Tomlinson, 2011). Government should provide public goods and services and manage public assets, for example, providing floods and coastal protection, emergency management, public health and safety measures and natural resources protection as well as managing public assets such as public land, natural parks and reserve systems and government owned infrastructure. Again, government on behalf of community should primarily be responsible for managing risks to public goods and assets (including natural environment) and government service delivery and creating an institution, market and regulating environment that supports and promote private adaptation (Roberts, 2008). Policy instruments, such as land use planning; codes and standards of environmental or public health legislation should play a role and provide a guideline in clarifying and strengthening incentives and responsibility. In South Africa, officials at the municipal level lack clear understanding of these environmental tools and processes, and such a gap had led to a rapidly changing urban and rural landscape, alteration of livelihoods opportunity and wealth distribution, which in turn had widened vulnerability of many communities and stakeholders and their capacity to adapt to long term risk (Roberts, 2008; Tomlinson, 2011). Planning for environmental, risk and hazards at the municipal level are faced with many challenges associated with service delivery.

\section{Challenges Associated with Planning for Service Delivery}

Municipalities in South Africa as a lower sphere of government are directly mandated by the Constitution of 1996 and other legislation to render services to the communities and making sure that such services are sufficient and sustainable. However, in reality many local municipalities are still struggling to affect their developmental mandate to plan for the provision of potable water, electricity, road and waste management, and infrastructural services in their areas of jurisdiction (Harpe, 2012). IDP is an important tool because of its emphasis on integration and its drive to be strategic, attempts to overcome a pre-emptive dependency on planning by sectors as opposed to planning to address local development issues. However, IDP processes have been clouded by diverse challenges including financial, skills shortage and poor participation of the communities (Madzivhandila \& Asha, 2012). Current trends of strategising through IDP are paying less attention to the planning priority and development strategies of spheres of government. Similarly, some relevant departments from national and provincial spheres have not work tirelessly to ensure that municipal priorities are included in their annual performance plans and budget. Some departments still deliver services within municipal and ward boundaries without consultation with the local officials and taking into account activities of other department. Moreover, separate, uncoordinated planning and budgeting process and different planning structures and mechanism have contributed to lack of integrated planning and delivery at grassroots level. The outcome of this 
functional disunity among departments and municipalities result into disintegrated, dysfunctional, fragmented and unsustainable investment of scarce resources. Examples are construction of schools without teachers, houses without water, and settlements without employment. IDP requires all sectors to contribute to local priority issues; however, the capacity to coordinate and integrate planning and budgeting at the local level is still a challenge. Lack of capacity to coordinate development planning and pervasive corruption is still a big obstacle to the majority of municipalities; hence the current trends of environmental challenges associated with climate change had added into the tension between environment and development.

It is evident that many industrial countries and international agencies have paid little attention to the reduction of greenhouse gas emissions. The focus has been to less immediate environmental concern and less local and political significant (Mukheibir \& Ziervogel, 2007; Revi, 2008; Roberts, 2008). It is still difficult to convince decision makers particularly at a municipal level to consider the need for a climate strategy when the climate projections cover a longer time horizon than the political and development framework. Resources and human capacity are still concentrated at the national and provincial sphere whereas, municipalities are still not capacitated for implementation of operational issues related to climate change. With the absence of legislative framework, not all municipalities are undertaking comprehensive and consistent adaptation planning to climate change related problems (Harpe, 2012). For instance all three municipalities' IDP consulted, namely, Lepelle-Nkumpi (2006-2011), Molemole (2008/2009) and Polokwane Local Municipality (2010/2011) have not identified climate change as a challenge to the provision of service delivery and there is little or no effort to formulate a consolidated or coordinated approach to adaptation to projected climate impacts among them. There is a need to address this disjuncture urgently as it is this that many people are directly affected by climateinduced impacts and it is at this level that institutional solutions can be introduced. Increase in the volume of rainfall, intensity of storms, and incidence of natural disasters for example, has put additional stress on infrastructure, building, and environmental conditions in rural areas. The potential barriers to the coordination of climate change issues at the local level include, low local human capacity for planning; limited knowledge and understanding of climate issues; limited financial resources and competing priorities (Revi, 2008). Municipal planning process is guided by the goals that local public officials, representatives, and communities seek to advance. These individuals and institutions are inclined towards maintaining the status quo. Minimising the impacts that climate change will have on municipalities and their inhabitants will require that they make concerted effort to protect natural systems, the built environment, and human population. Also, government should include representation from different levels of the municipal governance, communities and other stakeholders in the process of integrating climate change issues into the IDP process.

\section{Integration of Climte Change in Municipal Planning}

Many countries particularly in Africa made a late start in engaging with the question of climate change despite early environmentalist and academic position on this question (Ayinde et al. 2010). According to Ayinde et al. (2010), the reluctance of the sceptics on the existence of climate change is still prevalent and widely debated amongst natural scientists. On one hand, 'sceptics' say that the earth is not warming to the extent that it could be called a crisis, in fact some even suggest that the earth is getting colder; however, on the other hand some 'scientists' are stressing that climate change is bearing a detrimental effects not only to the environment, but to the entire ecological system (Totty, 2009; Ayinde et al., 2010). The current evidence of high temperatures, rising sea levels, low rainfall, drought, floods and acid rain amongst others are linked to the existence of climate change. In recent years, climate change has emerged as an important extension of environmental management mandates formulated after 1994 in South Africa, when new local government structures began to emerge in response to the changing policy and legislative policies with specific environmental management mandate and focus. Totty, (2009) argue that, the management of climate change impacts as an extension of existing risk management should build on existing effective risk and hazard arrangement.

One of important part of facilitating the integration of climate change to the existing risk and hazard assessment is the need to initiate and provide improved natural hazard risk assessment, management and mitigation capacity that respond to major disaster among the municipal officials dealing with environmental management (Gordon, 2005; Revi, 2008; Roberts, 2008). This process may require the redirection of investments and programmes in order to build new alliances between wide ranges of actors not often in engagement. Also, IDP process should create advocacy among local politicians and civil servant, consider climate change significance in municipal plans and in decision making and channelling staff and funds in climate change initiatives (Gordon, 2005). In these sense, a successful process of integrating climate change at a municipal level requires the cooperation of both government official and other stakeholders (business, communities and non-profit organisations).

Identifying the roles of government in adapting to climate change is the first step in building a coordinated 
approach (Gordon, 2005). Gordon (2005) asserts that, government at all its spheres should combine a response required to tackle the impact of climate change. Once the roles of each sphere are broadly agreed, responsibility for specific tasks should be stipulated. The capacity, knowledge and experience should inform the responsibility and accountability of a specific sphere (Carmin, Roberts \& Anguelovski, 2009). National and provincial government may provide guidelines and draft policies to facilitate the process of addressing climate change; however, local government should be on the frontline in dealing with the impact of climate change because they have a critical role to play in ensuring that particular local circumstances are adequately considered in the overall adaptation responses and in involving the local communities directly in efforts to facilitate effective change (Revi, 2008; Roberts, 2008; Carmin et al., 2009). Again, local government structures are strongly positioned to inform other sphere about the community needs by directly communicating with communities and responding appropriately and in a timely manner to local changes. Municipalities should be capacitated with skills and financial resources to integrate climate change in their continued efforts to facilitate management of risks and hazards to public assert and service delivery (Roberts, 2008). This process should also ensure policies and regulation including local planning and development regulation, incorporate climate change consideration; they should facilitate building resilience and adoptive capacity in the local community, including through providing information about relevant climate change risks; contribute appropriate resources to prepare, prevent, respond and recover from detrimental climate impacts. The other important part for municipalities to consider is working in partnership with communities and Non-Governmental Organisations (NGO's), business and other key stakeholders to manage the risks and impacts associated with climate change.

Government at all levels, businesses, households and the communities at large have important, complementary and differentiated roles in adapting to the impacts of climate change (Revi, 2008). However, given that a number of stakeholders have little or no knowledge on climate change issues, the development of a framework linking dialogue, engagement and action would be a useful step. For communities and other stakeholder to participate in dealing with climate change impacts, government on its capacity should make them aware of the risks and responsibilities for managing them in order to take steps to understand the magnitude and nature of the specific risks to their assets and activities in order to develop and implement strategies and actions to manage them (Revi, 2008). It is not feasible nor appropriate for government to bear all the cost of adopting to the impacts of climate change, it would also be inefficient and inappropriate for government to make decision on behalf of business and individuals that are better placed to understand and manage their own risks (Revi, 2008; Roberts, 2008). So, it is important for local municipality to capacitate communities to deal with climate change appropriately by recognising and empowering them.

\section{Conclusion}

Climate change issues need to be rooted in local realities that centre on avoiding or limiting impacts from, for instance drought, heavy rainfall, ecological change and water supply constrains brought about by climate change. The integration of climate-sensitive actions into developmental planning should become common place in all municipal departments and their strategic plans. Minimising the impact of climate change requires that municipalities to develop and implement adaptation plans and linking such plans to local priorities and on-going initiatives. Government should therefore develop a framework for adaptation to climate change at the municipal level in order to prioritise the most urgent local adaptation activities and identify the required local human and financial resources. This framework should provide a link between national, provincial and local policy, political institutional arrangement and intervention. Furthermore, the framework should serve as a platform for dialogue between public and private stakeholders. Such an integration of stakeholders will allow for the development of early warning system, where daily and seasonal weather forecast is monitored to identify any pending impacts and potential disaster to the communities.

\section{References}

Ayinde, O. E., Ajewole, O.O., Ogunlade, I. \& Adewumi, M.O. 2010. Empirical analysis of agricultural production and climate change: a case study of Nigeria. Journal of Sustainable Development in Africa, 12(12):275-283.

Carmin, J., Roberts, D. \& Anguelovski, I. 2009. Planning Climate Resilient Cities: Early Lessons from Early Adapters. Washington D.C: World Bank.

Department of Environmental Affairs and Tourism (DEAT) 2004. National Climate Change Response Strategy for South Africa. Pretoria: DEAT.

Department of Environmental Affairs and Tourism 2011. South African Government Position on Climate Change. http://www. climateaction.org.za/cop17-cmp7/sa-government-position-on-climate-change (date accessed: 16 April 2013).

Gordon, G.L. 2005. Strategic Planning for Local Government. Washington D.C: International City/Country Management Association. 
Hahn, M.B., Riederer, A.M. \& Foster, S.O. (2009) The livelihood vulnerability index: a pragmatic approach to assessing risks from climate variability and change, a case study in Mozambique. Global Environmental Change, 19:74-88.

Harpe, J. 2012. Integrated Development Planning at Local Government Level: A Briefing Note Based on South African Experience. The Hague: International Water and Sanitation Centre

Khandlhela, M. \& May, J. 2006. Poverty, vulnerability and the impact of flooding in the Limpopo Province, South Africa. Net Hazards, 58:275-287.

Lepelle-Nkumpi Local Municipality 2006. Integrated Development Plan (2006-2011). Polokwane: Lepelle-Nkumpi Local Municipality

Madzivhandila, T.S. \& Asha, A.A. 2012. Integrated development planning process and service delivery challenges for South Africa's local municipalities. Journal of Public Administration, 47(1.1):369-378.

Molemole Local Municipality 2008. Integrated Development Plan (2008/2009). Polokwane: Molemole Local Municipality.

Mukheibir, P. \& Ziervogel, G. 2007. Developing a municipal adaptation plan (MAP) for climate change: the city of Cape Town. Environment and Urbanisation, 19(1):143-158.

Polokwane Local Municipality 2010. Integrated Development Plan (2010/2011). Polokwane: Polokwane Local Municipality

Revi, A. 2008. Climate change risk: an adaptation and mitigation agenda for Indian cities. Environment and Urbanisation, 20(1):207-229.

Roberts, D. 2008. Thinking globally, acting locally-institutionalising climate change at the local government level in Durban South Africa. Environment \& Urbanisation, 20(2):521-537.

Tomlinson, M.R. 2011. Managing the risk in housing delivery: local government in South Africa. Habitat International, 35:419-425.

Totty, M. 2009. What Global Warming? New York: The Wall Street Journal. 